\title{
Salt-excluding artificial water channels exhibiting enhanced dipolar water and proton translocation
}

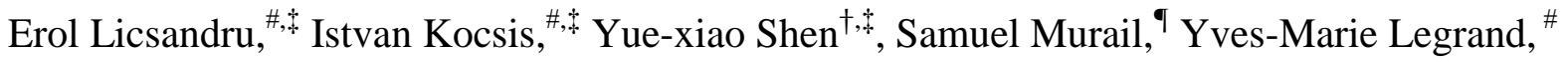
Arie van der Lee ${ }^{\#}$, Daniel Tsai, ${ }^{\dagger}$ Marc Baaden, ${ }^{\top}$ Manish Kumar, ${ }^{\dagger}$ Mihail Barboiu**,

" Adaptive Supramolecular Nanosystems Group, Institut Europeen des Membranes, ENSCM-UMII-UMR CNRS 5635, Place Eugene Bataillon CC047, Montpellier, F-34095, France

${ }^{\dagger}$ Department of Chemical Engineering, Pennsylvania State University, University Park, PA, 16802, USA

"Laboratoire de Biochimie Théorique, CNRS - UPR9080, Institut de Biologie Physico-Chimique, 13, rue Pierre et Marie Curie, F-75005 Paris, France

*To whom correspondence should be addressed. E-mail: mihail-dumitru.barboiu@univ-montp2.fr

ॠ These authors contributed equally to this work. 


\section{Materials and methods}

\section{Chemical synthesis}<smiles>[R]NO[I-]</smiles>

isocyanate<smiles>[R]NC(=O)NCCc1c[nH]cn1</smiles>

monourea compound

All of the compounds have been synthesized following the general scheme shown above. The histamine $(30 \mathrm{mmol})$ is mixed with the corresponding equimolar amount of isocyanate, with sonication. The mixture was solubilized in $10 \mathrm{ml}$ of THF (tetrahydrofuran), $5 \mathrm{ml}$ of ethylacetate, and $10 \mathrm{ml}$ of dimethylacetamide. The reaction mixture was heated to $120^{\circ} \mathrm{C}$ for 15 minutes. When the precipitation begins $5 \mathrm{ml}$ of acetonitrile are added and the heating is maintained for another hour. The resulting products as the white powders are then filtered and washed with methanol on the filter paper. The exceptions to the protocol are compound HC4 for which the reaction temperature is $60^{\circ} \mathrm{C}$ and compounds $\mathbf{H C 6}, \mathbf{H C}, \mathbf{R}-\mathbf{H C} 8$ and S-HC8 for which the reaction temperature is $80^{\circ} \mathrm{C}$. Compound $\mathrm{HC} 4$ is soluble in the reaction mixture and therefore the purification procedure is as follows. The reaction mass is evaporated under vacuum in a round bottomed flask and the compound is then recrystallized from $\mathrm{CHCl}_{3}$.

Alternatively a microwave reactor can be used. The procedure is the following: the isocyanate is dissolved in $5 \mathrm{ml}$ of acetonitrile and added over the amine in the microwave reactor. The reaction is performed at $140^{\circ} \mathrm{C}$ under high stirring for 15 minutes. The product is then filtered and washed with methanol. In the case of compound $\mathrm{HC} 4$ the temperature is $50^{\circ} \mathrm{C}$ and for compounds HC6, HC8, R-HC8 and S-HC8 is $90^{\circ} \mathrm{C}$.

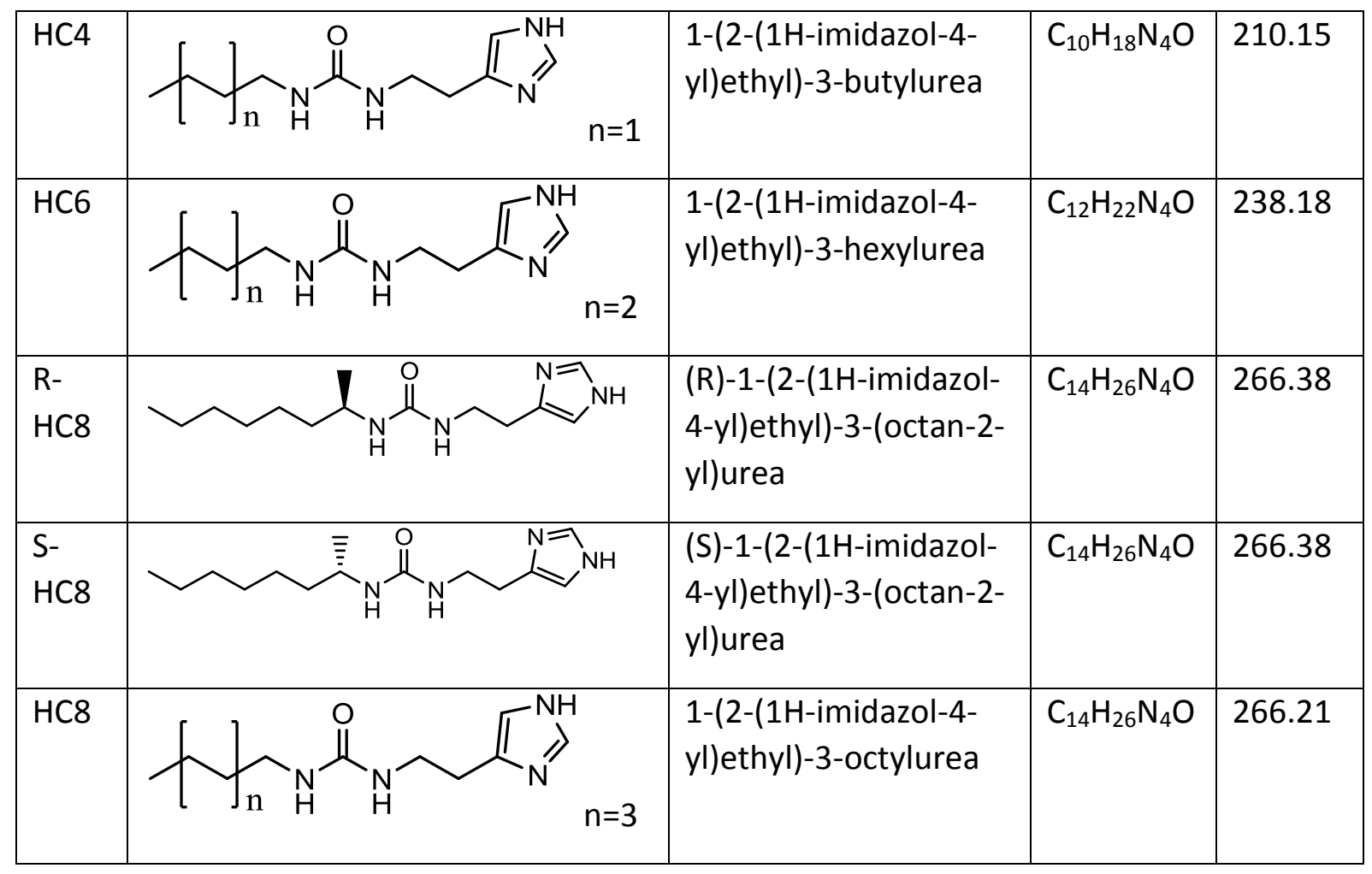


1-(2-(1H-imidazol-4-yl)ethyl)-3-butylurea, HC4 : ${ }^{1} \mathrm{H}-\mathrm{RMN}$ (DMSO-d6, $\left.300 \mathrm{MHz}\right) \delta(\mathrm{ppm})=$ $0,86(\mathrm{t}, 3 \mathrm{H}, \mathrm{CH} 3 \mathrm{CH} 2) ; 1,30(\mathrm{~m}, 4 \mathrm{H}, \mathrm{CH} 3 \mathrm{CH} 2 \mathrm{CH} 2 \mathrm{CH} 2) ; 2,58(\mathrm{t}, 2 \mathrm{H}, \mathrm{NHCH} 2 \mathrm{CH} 2) ; 2,96(\mathrm{q}, 2 \mathrm{H}$, $\mathrm{CH} 2 \mathrm{CH} 2 \mathrm{NH}$ ) ; 3,21 (q, 2H, CH2CH2NH) 5,75 (s mod, $1 \mathrm{H}, \mathrm{NHCH} 2$ ) ;5.83 (s mod, $1 \mathrm{H}, \mathrm{NHCH} 2$ ) ; 6,78 (s,1H,C CHNH imidazole) ; 7,55 (s,1H,N CHNH imidazole) $\mathrm{ESI}^{+}-\mathrm{MS}: \mathrm{M}^{*+}=211.1$.

1-(2-(1H-imidazol-4-yl)ethyl)-3-hexylurea, HC6 : RMN $^{\mathbf{1}} \mathbf{H}$ (DMSO-d6, $\left.300 \mathrm{MHz}\right) \delta(\mathrm{ppm})=$ 0,86 (t, 3H, CH3CH2) ; 1,24-1.34 (m, 8H, CH3(CH2)4CH2) ; 2,57 (t, 2H, NHCH2CH2) ; 2,96 (q, $2 \mathrm{H}, \mathrm{CH} 2 \mathrm{CH} 2 \mathrm{NH}$ ) ; 3,21 (q, 2H, CH2CH2NH) 5,75 (s mod, $1 \mathrm{H}, \mathrm{NHCH} 2$ ) ;5.84 (s mod, $1 \mathrm{H}$, $\mathrm{NHCH} 2) ; 6,75$ (s,1H,C CHNH imidazole) ; 7,54 (s,1H,N CHNH imidazole) $\mathrm{ESI}^{+}-\mathrm{MS}=239.1$

1-(2-(1H-imidazol-4-yl)ethyl)-3-octylurea, HC8 : RMN $^{1} \mathbf{H}$ (DMSO-d6, $\left.300 \mathrm{MHz}\right) \delta(\mathrm{ppm})=$ 0,86 (t, 3H, CH3CH2) ; 1,25-1.34 (m, 12H, CH3(CH2)6CH2); 2,58 (t, 2H, NHCH2CH2); 2,95 (q, $2 \mathrm{H}, \mathrm{CH} 2 \mathrm{CH} 2 \mathrm{NH}$ ) ; 3,21 (q, 2H, CH2CH2NH) 5,74 (s mod, $1 \mathrm{H}, \mathrm{NHCH} 2$ ) ;5.82 (s mod, $1 \mathrm{H}$, $\mathrm{NHCH} 2) ; 6,76$ (s,1H,C CHNH imidazole) ; 7,52 (s,1H,N CHNH imidazole). $\mathrm{ESI}^{+}-\mathrm{MS} \mathrm{M}^{*+}=267.1$.

(R)-1-(2-(1H-imidazol-4-yl)ethyl)-3-(octan-2-yl)urea, R-HC8: RMN ${ }^{1} \mathbf{H}$ (DMSO-d6, 300 MHz) $\delta$ $(\mathrm{ppm})=0,85(\mathrm{t}, 3 \mathrm{H}, \mathrm{CH} 3 \mathrm{CH} 2) ; 0,97(\mathrm{~d}, 3 \mathrm{H}, \mathrm{CH} 3 \mathrm{CHHC2}) 1,24(\mathrm{~m}, 10 \mathrm{H}, \mathrm{CH} 3(\mathrm{CH} 2) 5 \mathrm{CH} 2) ; 2,57$ (t, $2 \mathrm{H}, \mathrm{NHCH} 2 \mathrm{CH} 2$ ) ; 3,20 (q, 2H, CH2CH2NH); 3,53 (m, 1H, CH2CH3CHNH); 5,67 (s mod, $1 \mathrm{H}$, $\mathrm{NHCH} 2$ ) ;5.69 (s mod, $1 \mathrm{H}, \mathrm{NHCH} 2) ; 6,82$ (s,1H,C CHNH imidazole) ; 7,51 (s,1H,N CHNH imidazole) $\mathrm{ESI}^{+}-\mathrm{MS}: \mathrm{M}^{*+}=267.2$.

(S)-1-(2-(1H-imidazol-4-yl)ethyl)-3-(octan-2-yl)urea, S-HC8 : RMN ${ }^{1} \mathrm{H}$ (DMSO-d6, $300 \mathrm{MHz}$ ) $\delta$ $(\mathrm{ppm})=0,85(\mathrm{t}, 3 \mathrm{H}, \mathrm{CH} 3 \mathrm{CH} 2) ; 0,97(\mathrm{~d}, 3 \mathrm{H}, \mathrm{CH} 3 \mathrm{CHHC2}) 1,23(\mathrm{~m}, 10 \mathrm{H}, \mathrm{CH} 3(\mathrm{CH} 2) 5 \mathrm{CH} 2) ; 2,57$ (t, $2 \mathrm{H}, \mathrm{NHCH} 2 \mathrm{CH} 2$ ) ; 3,20 (q, 2H, CH2CH2NH); 3,49 (m, 1H, CH2CH3CHNH); 5,66 (s mod, $1 \mathrm{H}$, $\mathrm{NHCH} 2$ ) ;5.69 (s mod, $1 \mathrm{H}, \mathrm{NHCH} 2) ; 6,75$ (s,1H,C CHNH imidazole) ; 7,51 (s,1H,N CHNH imidazole) $\mathrm{ESI}^{+}-\mathrm{MS}: \mathrm{M}^{*+}=267.2$.

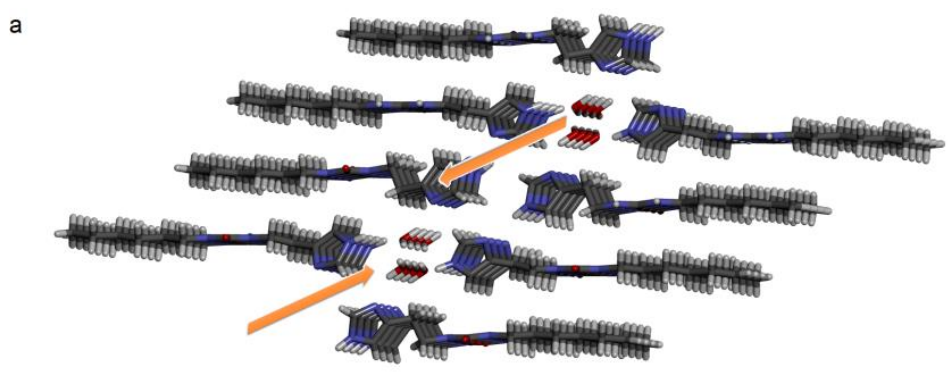

b

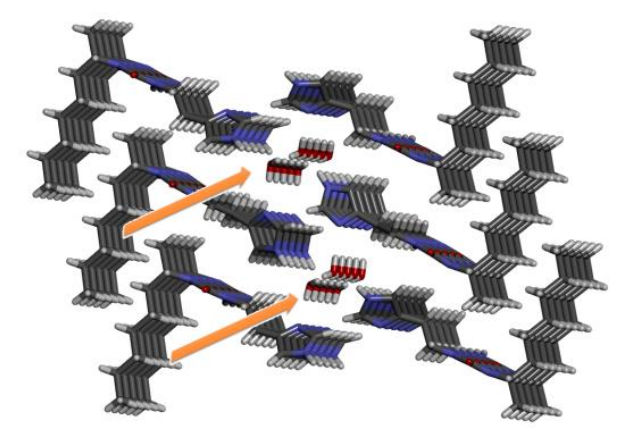

Figure S1. Water-wires dipolar orientations in successive channels showing: a) opposite water dipolar orientations in successive channels of HC6 and b) a unique dipolar orientation for all the water-channels of chiral R-HC8 and S-HC8 (not shown but similar) 
Water transport experiments: Phosphatidylcholine (chicken egg, PC) and phosphatidylserine (porcine brain, PS) were purchased from Avanti Polar Lipids. Cholesterol (Chl) was obtained from Sigma. They were used without further purification. Two incorporation methods were employed to introduce the imidazole compounds within the lipid phase.

Method 1: Pre-mix assay: Liposomes were prepared using the film rehydration method. (S1) The imidazole compounds, in chloroform/methanol mixture $\left(\mathrm{CHCl}_{3} / \mathrm{MeOH}, \mathrm{v} / \mathrm{v}: 1 / 1\right)$ were added to the $1 \mathrm{mg} \mathrm{PC} / \mathrm{PS} / \mathrm{Chl}$ mixture with a molar ratio of $4 / 1 / 5$. The solution was dried on a rotary evaporator and subsequently under high vacuum to remove residual solvent. After rehydration with $1 \mathrm{ml}$ buffer containing $10 \mathrm{mM}$ Hepes $(\mathrm{pH}=7), 100 \mathrm{mM} \mathrm{NaCl}$ and $0.01 \%$ $\mathrm{NaN}_{3}$, the suspension was incubated with stirring at $4{ }^{\circ} \mathrm{C}$ for $24 \mathrm{~h}$ and extruded through 0.2 $\mu \mathrm{m}$ track-etched filters for 10 times (Whatman, UK) to obtain monodisperse unilamellar vesicles, the size of which was characterized by dynamic light scattering (Zetasizer Nano, Malvern Instruments Ltd., UK). The water permeability tests were conducted on a stoppedflow instrument (SF-300X, KinTek Corp., USA). Exposure of vesicles to hypertonic osmolyte (10 mM Hepes, $300 \mathrm{mM} \mathrm{NaCl}, 0.01 \% \mathrm{NaN}_{3}$ and $\mathrm{pH}=7$ ) resulted in the shrinkage of the vesicles due to an outwardly directed osmotic gradient. The abrupt decrease of the vesicle size lead to the increase in the light scattering at $90^{\circ}$ according to the Rayleigh-Gans theory applied to this system. (S2) The changes of light scattering caused by vesicle shrinkage were recorded at a wavelength of $600 \mathrm{~nm}$.

Method 2: Post-injection assay: Liposomes were prepared using the same film rehydration method as above. A PC/PS/Chl mixture with a molar ratio of $4 / 1 / 5$ was dissolved in chloroform/methanol mixture $\left(\mathrm{CHCl}_{3} / \mathrm{MeOH}, \mathrm{v} / \mathrm{v}: 1 / 1\right)$. The solution was dried on a rotary evaporator and subsequently under high vacuum to remove residual solvent. After rehydration with $1 \mathrm{ml}$ buffer containing $200 \mathrm{mM}$ sucrose and $10 \mathrm{mM}$ PBS (pH=6.4), the suspension was extruded through $0.1 \mu \mathrm{m}$ track-etched filters for 21 times (Whatman, UK) to obtain monodisperse unilamellar vesicles, the size of which was characterized by dynamic light scattering (Zetasizer Nano, Malvern Instruments Ltd., UK). The aliquot of the compounds dissolved in DMSO have been added to the liposomes. The amphiphilic imidazole derivatives are poorly water soluble but are used at concentrations where precipitation does not occur. The water permeability tests were conducted on a stoppedflow instrument (SFM3000+MOS450, Bio-Logic SAS, Claix, France). Exposure of vesicles to hypertonic osmolyte (400 sucrose) in the same buffer resulted in the shrinkage of the vesicles due to an outwardly directed osmotic gradient. The changes of light scattering were recorded at a wavelength of $345 \mathrm{~nm}$.

The abrupt change of the vesicle size lead to variation in the light scattering at $90^{\circ}$ according to the Rayleigh-Gans theory applied to this system and could be fitted in the form of the sum of two exponential functions. The osmotic permeability $\left(P_{f}\right)$ was calculated as following: $(S 3)$

$$
P_{f}=\frac{k}{\left(\frac{S}{V_{0}}\right) \times V_{W} \times \Delta_{o s m}}
$$

where $k$ is the exponential coefficient of the change in the light scattering (the choice of using the larger value $k_{1}$ or the smaller value $k_{2}$ depends on the light scattering response of the vesicles compared to the control liposomes. See the results for details); $S$ and $V_{0}$ are the initial surface area and volume of the vesicles, respectively; $V_{w}$ is the molar volume of water, and $\Delta_{o s m}$ is the osmolarity difference. 
Channel and lipid concentration calibration: $200 \mu \mathrm{l}$ imidazole channels solutions (from 0 $\mathrm{mg} / \mathrm{l}$ to $0.5 \mathrm{mg} / \mathrm{l})$, in $10 \mathrm{mM}$ Hepes $(\mathrm{pH}=7), 100 \mathrm{mM} \mathrm{NaCl}, 0.01 \% \mathrm{NaN}_{3}$ and $8 \% n$-octyl- $\beta$-Dglucoside (OG), were mixed with $200 \mu$ control liposomes. The control liposomes were first prepared using the film rehydration method in the same buffer without OG, containing 1 $\mathrm{mg} / \mathrm{ml} \mathrm{PC/PS/Chl} \mathrm{lipids} \mathrm{with} \mathrm{a} \mathrm{molar} \mathrm{ratio} \mathrm{of} 4 / 1 / 5$. The liposomes were further extruded through $0.2 \mu \mathrm{m}$ track-etched filters for 10 times (Whatman, UK) to obtain monodisperse unilamellar vesicles. The obtained solutions (final channels' concentration: $0 \mathrm{mg} / \mathrm{l}$ to 0.25 $\mathrm{mg} / \mathrm{l}$ ) were scanned on a UV-Vis spectrophotometer (Nanodrop 2000c, Thermo Fisher Scientific Inc., IL). We found all channels solutions had specific UV absorbance at $230 \mathrm{~nm}$ (see Figure S4). For vesicles used for water transport studies, the channels were incorporated into bilayers during the film rehydration. $200 \mu \mathrm{l}$ monodisperse vesicles after extrusion were mixed with $200 \mu \mathrm{l}$ the same HEPES buffer containing $8 \%$ OG and the absorbance was measured at $230 \mathrm{~nm}$.

The insertion efficiency of the channels was calculated based on the calibration curves: $\mathrm{PC} / \mathrm{PS} / \mathrm{Chl}$ lipids solutions (from $0 \mathrm{mg} / \mathrm{l}$ to $1.0 \mathrm{mg} / \mathrm{l}$ ) with a molar ratio of $4 / 1 / 5$ were prepared in buffer containing $10 \mathrm{mM}$ HEPES ( $\mathrm{pH}=7), 100 \mathrm{mM} \mathrm{NaCl}, 0.01 \% \mathrm{NaN}_{3}$ and $4 \% n-$ octyl- $\beta$-D-glucoside (OG). The solutions were scanned on a UV-Vis spectrophotometer and we found the UV absorbance of the lipid solutions increased with the concentrations. We chose $280 \mathrm{~nm}$ and the absorbance at this wavelength was proportional to the concentration. When the extruded liposomes (initially $1 \mathrm{mg} / \mathrm{ml}$ ) were measured at this wavelength, the actual concentration was $0.78 \mathrm{mg} / \mathrm{ml}$.

\section{Proton transport experiments}

Method 1: HPTS assay: Egg yolk L- $\alpha$-phosphatidylcholine (EYPC, $600 \mu \mathrm{l}, 790 \mu \mathrm{mol}$ in $\mathrm{CHCl}_{3}$ ) was dissolved in $\mathrm{CHCl}_{3} / \mathrm{MeOH}$ mixture. The solution was evaporated under reduced pressure and the resulting thin film was dried under high vacuum for $2 \mathrm{~h}$. The lipid film was hydrated in $1.2 \mathrm{~mL}$ of phosphate buffer containing $10 \mathrm{mM}$ sodium phosphate $(\mathrm{pH}=6.4), 100 \mathrm{mM} \mathrm{NaCl}$ and $10 \mu \mathrm{M}$ HPTS (pyranine, 8-hydroxypyrene-1,3,6-trisulfonic acid trisodium salt) for $40 \mathrm{~min}$. During the hydration, the suspension was subject to at least 5 freeze-thaw cycles (liquid nitrogen vs. water at room temperature). The large multilamellar liposome suspension ( $1 \mathrm{ml})$ was extruded through a $0.1 \mu \mathrm{m}$ track-etched filter (Whatman, UK) for 21 times, affording a suspension of unilamellar vesicles with an average diameter of $100 \mathrm{~nm}$. The vesicle suspension was further purified from the extravesicular dye by size exclusion chromatography (stationary phase: Sephadex G-50, mobile phase: phosphate buffer) and diluted with the same buffer to give a stock solution with a lipid concentration of $11 \mathrm{mM}$ (assuming $100 \%$ of lipid was incorporated into liposomes).

$0.1 \mathrm{ml}$ of HPTS-loaded vesicles (stock solution) was suspended in $1.9 \mathrm{ml}$ of $10 \mathrm{mM}$ sodium phosphate $(\mathrm{pH}=6.5)$ and $50 \mathrm{mM} \mathrm{Na}{ }_{2} \mathrm{SO}_{4}$ solution, and placed into a fluorimetric cell. The emission of HPTS at $510 \mathrm{~nm}$ was monitored at $\lambda_{\text {ex } 1}=403 \mathrm{~nm}$ and $\lambda_{\text {ex } 2}=460 \mathrm{~nm}$ (PerkinElmer LS55 fluorescence spectrometer). During the experiment, $20 \mu \mathrm{l}$ of a 0-40 mM DMSO solution of the imidazole compounds was added at $t=60 \mathrm{~s}$, followed by injection of $20 \mu \mathrm{L}$ of $1 \mathrm{nM}$ solution of valinomycin in DMSO at $\mathrm{t}=100 \mathrm{~s}$. At time $=150 \mathrm{~s}$ an injection of $21 \mu \mathrm{L}$ of $0.5 \mathrm{M}$ aqueous $\mathrm{NaOH}$. Maximal possible changes in dye emission were obtained at $t=500 \mathrm{~s}$ when the aqueous compartment of liposomes was equilibrated with extravesicular solution by lysis of the 
liposomes with detergent $(40 \mu \mathrm{l}$ of $5 \%$ Triton $\mathrm{X} 100)$. The $\mathrm{pH}$ values were calculated for each point from the HPTS emission intensities according to the calibration equation $\mathrm{pH}=1.1684 \cdot \log \left(I_{0} / I_{1}\right)+6.9807$, where $I_{0}$ is the emission intensity at $\lambda_{\text {ex } 2}=460 \mathrm{~nm}$ and $I_{1}$ is the emission intensity at $\lambda_{\mathrm{ex} 1}=403 \mathrm{~nm}$.

To calculate $\mathrm{EC}_{50}$ and Hill coefficient $n$, we used the fractional activity $\mathrm{Y}$. Y was calculated for each curve using the normalised value of $\mathrm{I}_{460} / \mathrm{I}_{403}$ (just before lysis of the vesicles), from 0 (ratio for the blank) to 1 (highest ratio obtained, i.e. a plateau). We expressed $Y$ as a function of time, and we performed fittings using a 2-parameter equation, which is, Hill equation :

$$
Y=\frac{1}{1+\left(E C_{50} /[C]\right)^{n}}
$$

The Hill coefficient is an indication the cooperativity of the channel forming elements. There is two ways to find Hill coefficient $n$ and EC50: either fitting of the experimental curve using the Hill function (as we did), or using the expression

$$
\log \left(\frac{Y}{1-Y}\right)=n \log C-n \log E C_{50}
$$

where $n$ is the slope of the curve and $n^{*} \log \left(E C_{50}\right)$ is the $\log (C)=0$ intercept value.

Method 2: Fluorescent dextran assay: $6 \mathrm{mg} / \mathrm{ml} \mathrm{PC}$, and $400 \mathrm{mmol} / \mathrm{ml}$ fluorescently labelled $\mathrm{pH}$-sensitive dextran (D-3305, Life Technologies) were first dissolved in buffer containing 10 $\mathrm{mM}$ HEPES $(\mathrm{pH}=6.4), 100 \mathrm{mM} \mathrm{KCl}$ and $4 \% \mathrm{w} / \mathrm{v}$ OG. The liposomes formed after being dialyzed for 36 hours and were subsequently extruded through $0.2 \mu \mathrm{m}$ track-etched filters (Whatman, UK). The resulting monodisperse unilamellar vesicles were further subject to size exclusion in order to remove the residual free dye. Because of the dilution of the size exclusion process, the purified liposomes, with $400 \mathrm{mM} / \mathrm{ml}$ fluorescent dextran only encapsulated inside the vesicles, contained approximately $3 \mathrm{mg} / \mathrm{ml} \mathrm{PC.} 1 \mu \mathrm{l}$ valinomycin $(0.5$ $\mathrm{mg} / \mathrm{ml}$ in DMSO) and $10 \mu \mathrm{l}$ imidazole compounds (different concentrations in DMSO) were then added to the $400 \mu \mathrm{l}$ fluorescent vesicles. After $5 \mathrm{~min}$, the mixture was mixed with same buffer at $\mathrm{pH}$ of 8.4 in stopped-flow experiments, which caused one $\mathrm{pH}$ unit gradient across the lipid bilayers ( $\mathrm{pH} 6.4$ inside the vesicles and $\mathrm{pH} 7.4$ outside the vesicles). The fluorescent signals $\left(\lambda_{\mathrm{ex}}=494 \mathrm{~nm}, \lambda_{\mathrm{em}}=521 \mathrm{~nm}\right)$ were recorded on the stopped-flow instrument (SF-300X, KinTek Corp., USA) at a fixed photomultiplier tube value of $571 \mathrm{~V}$. The fluorescent vesicles at different equilibrated $\mathrm{pH}$ without additions of valinomycin and imidazole compounds were prepared and tested on the stopped-flow for calibration $\mathrm{pH}=0.3151 \cdot F+4.2011$, where $F$ is the fluorescence. The proton flux is determined according to equations (2) (S4) and (3) (S5)

Where $B$ is the buffer capacity

$$
J_{H^{+}}=\frac{d p H}{d t} \times \beta
$$

$$
\beta=\frac{d n}{d p H}=2.303\left(\frac{K_{w}}{\left[H^{+}\right]}+\left[H^{+}\right]+\frac{c K_{a}\left[H^{+}\right]}{\left(K_{a}+\left[H^{+}\right]\right)^{2}}\right)
$$

Since stopped-flow measurements provide the kinetics of the fluorescence due to the proton transport with millisecond resolution, we further estimated the proton transport rate per assembled imidazole channel based on $J_{H^{+}} N_{A} V_{0} / N_{\text {Channel }}$, where $N_{A}$ is Avogadro's number, $V_{0}$ is the vesicle volume and $N_{\text {channel }}$ is the channel number per vesicle. 
As an example of the above calculation, let us consider the HC8 sample ( $38 \mu \mathrm{M})$, the radius of the liposome was $70 \mathrm{~nm}$. The sum of outer and inner surface areas was $\pi / 4 \times d^{2}+\pi / 4 \times(d-5)^{2}$ $=114,688 \mathrm{~nm}^{2}$, assuming that the bilayer thickness was $5 \mathrm{~nm}$. The average cross-sectional area of a lipid in average was $0.35 \mathrm{~nm}^{2},(S 6)$ and that of the l-quartet (not including the alkyl chain) was estimated as $0.7 \mathrm{~nm}^{2}$. The lipid (PC) mass was $0.4 \mathrm{ml} \times 3 \mathrm{mg} / \mathrm{ml}=1.2 \mathrm{mg}$. The molar lipid to HC8 compound ratio was 100 . Since 48 HC8 molecules assembled as a channel based on simulation, the molar lipid to channel ratio is 4,800 . The insertion number of the channel was 34 per vesicle. Here we assume all the channel compounds were incorporated into the liposomes (we do not have incorporation efficiency data for this method). The single-channel proton transport rate of this sample was $2.7 \pm 0.9$ protons/s channel $(n=3)$ after subtracting the background. Then we averaged four sets of HC8 samples $(7.6 \mu \mathrm{M}, 38 \mu \mathrm{M}, 76 \mu \mathrm{M}$ and 380 $\mu \mathrm{M})$ and obtained the single-channel proton transport rate of HC8 channel.
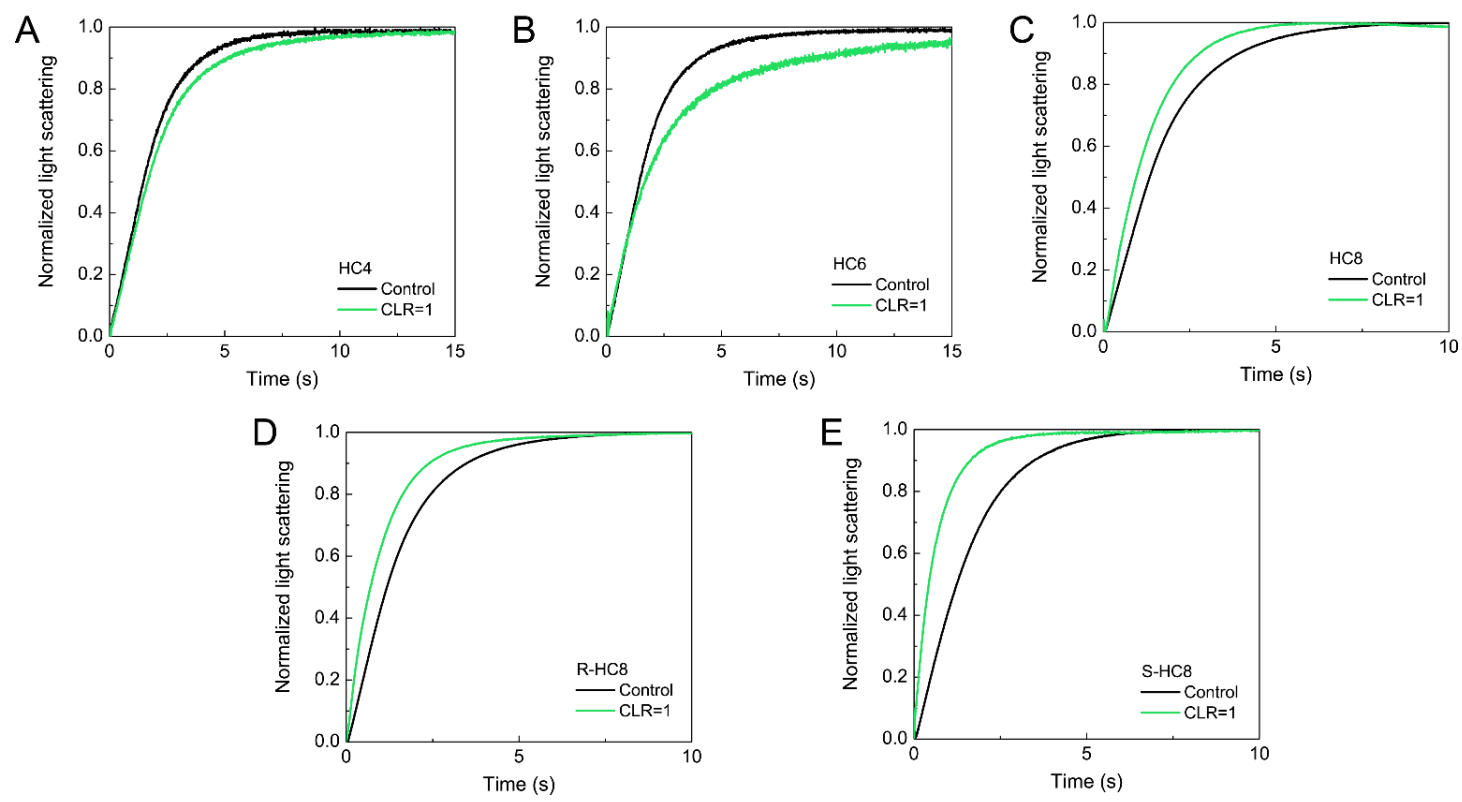

Figure S2. The stopped-flow traces from experiments on liposomes with different imidazole channels at weight channel to lipid ratio of $1(C L R=1)$ from the pre-mix assays. All the liposomes were abruptly exposed to a hypertonic solution of $200 \mathrm{mM} \mathrm{NaCl}$.
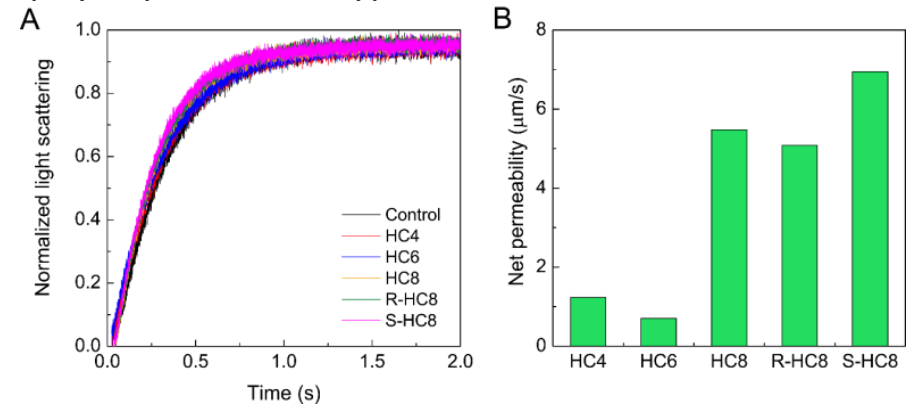

Figure S3. The water permeabilities of the channels assembled by different imidazole compounds were determined by stopped-flow light scattering experiments from the postmix assay. (A) The stopped-flow traces from experiments on liposomes with different imidazole channels at weight channel to lipid ratio of $1(C L R=1)$. All the liposomes were abruptly exposed to a hypertonic solution of $200 \mathrm{mM}$ sucrose. (B) The net permeability of the channels assembled by different imidazole compounds at CLR=1. 

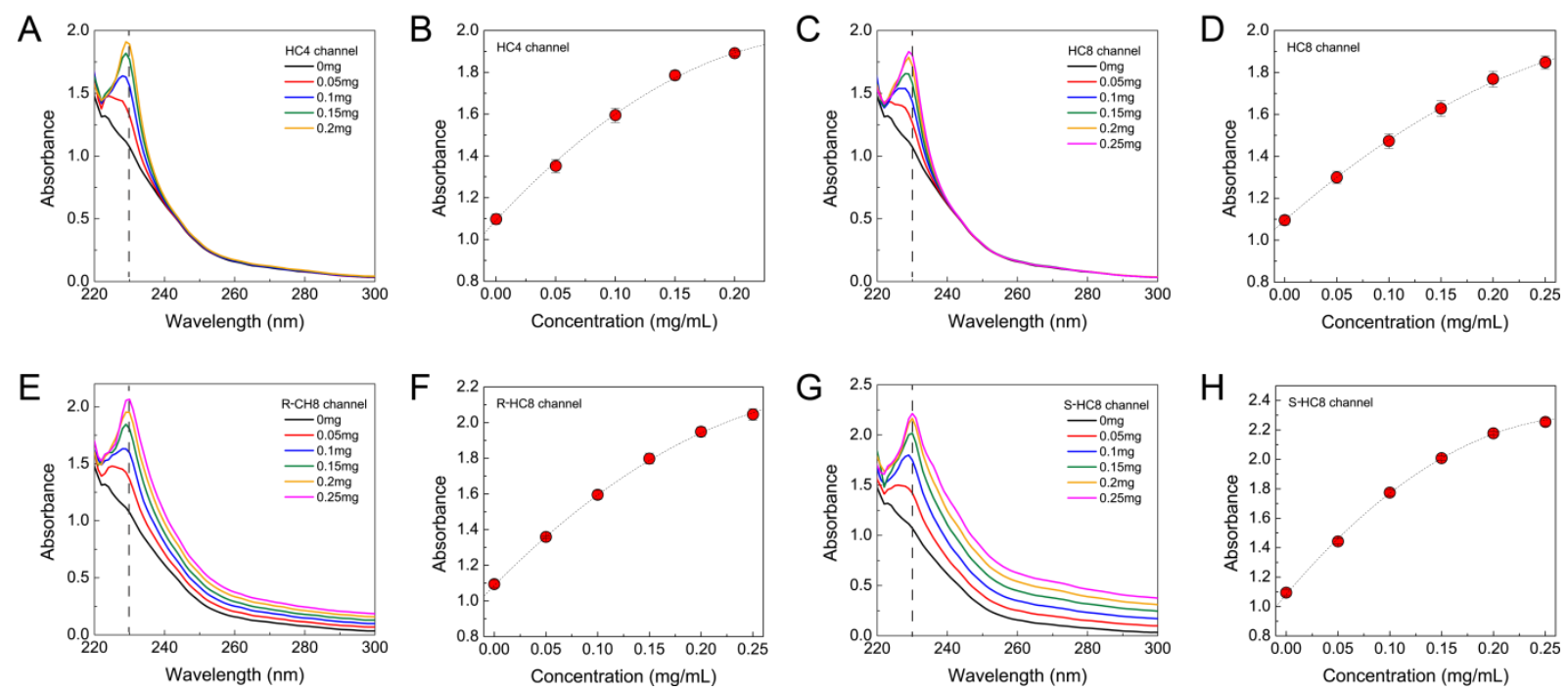

Figure S4. The UV spectra and calibration curves of different imidazole channels (from 0 to $0.25 \mathrm{mg} / \mathrm{L}$ ) in buffer containing $10 \mathrm{mM}$ HEPES (pH=7), $100 \mathrm{mM} \mathrm{NaCl}, 0.01 \% \mathrm{NaN}_{3}, 4 \% n$-octyl$\beta$-D-glucoside (OG) and $0.5 \mathrm{mg} / \mathrm{mL}$ extruded control liposomes. The control liposomes were first prepared using the film rehydration method in the same buffer without OG, containing $1 \mathrm{mg} / \mathrm{mL}$ PC/PS/Chl lipids with a molar ratio of $4 / 1 / 5$. The liposomes were further extruded through $0.2 \mu \mathrm{m}$ track-etched filters for 10 times to obtain monodisperse unilamellar vesicles. All these data were from triple measurements.

Table S1. The final concentrations after extrusion and the insertion efficiency of different imidazole compounds in liposomes. The vesicles contained $1 \mathrm{mg} / \mathrm{mL}$ PC/PS/Chl lipids with a molar ratio of $4 / 1 / 5$ at $C L R=1$ during film rehydration. All the results were from multiple measurements.

\begin{tabular}{cccc}
\hline & $\begin{array}{c}\text { Final concentration in } \\
\text { purified vesicles }(\mathrm{mg} / \mathrm{mL})\end{array}$ & $\begin{array}{c}\text { Initial concentration during } \\
\text { film rehydration }(\mathrm{mg} / \mathrm{mL})\end{array}$ & Insertion efficiency \\
\hline HC4 & $0.715 \pm 0.060$ & 1.0 & $71.5 \pm 6.0 \%$ \\
HC6 $^{\text {a }}$ & - & 1.0 & - \\
HC8 & $0.127 \pm 0.026$ & 1.0 & $12.7 \pm 2.6 \%$ \\
R-HC8 & $0.688 \pm 0.029$ & 1.0 & $68.8 \pm 2.9 \%$ \\
S-HC8 & $0.531 \pm 0.068$ & 1.0 & $53.1 \pm 6.8 \%$ \\
\hline
\end{tabular}

${ }^{a}$ HC6 imidazole compounds did not dissolve in detergent solution and the insertion efficiency could not be determined using this method. 
Table S2. Single channel permeability of different imidazole compounds assembled channels in both shrinking and swelling modes.

\begin{tabular}{cc}
\hline Channel & Single channel permeability in shrinking mode ${ }^{\text {a }}$ \\
\hline HC4 & $(2.5 \pm 0.5) \times 10^{3} \mathrm{H}_{2} \mathrm{O} / \mathrm{s}$ \\
HC6 $^{\text {b }}$ & - \\
HC8 & $(1.4 \pm 0.4) \times 10^{6} \mathrm{H}_{2} \mathrm{O} / \mathrm{s}$ \\
R-HC8 & $(7.9 \pm 2.1) \times 10^{5} \mathrm{H}_{2} \mathrm{O} / \mathrm{s}$ \\
S-HC8 & $(1.5 \pm 0.1) \times 10^{6} \mathrm{H}_{2} \mathrm{O} / \mathrm{s}$ \\
\hline
\end{tabular}

\footnotetext{
${ }^{a}$ The single channel permeability in shrinking mode was from pre-mix assay;

${ }^{b}$ Since we did not get insertion efficiency data from HC6, we did not calculate its single channel permeability.
}

Note: The single channel permeability was calculated based on the imidazole channel insertion, actual lipid concentration and channel configuration in lipids. Take one CLR=1 sample of HC8 as an example, the radius of the liposome was $72.5 \mathrm{~nm}$. The sum of outer and inner surface areas was $\pi / 4 \times d^{2}+\pi / 4 \times(d-5)^{2}=123,308 \mathrm{~nm}^{2}$, assuming that the bilayer thickness was $5 \mathrm{~nm}$. The average crosssectional area of a lipid in average was $0.287 \mathrm{~nm}^{2}$ (PC/PS/Chl lipids with a molar ratio of 4/1/5: the cross-sectional areas of PC and PS were $\sim 0.35 \mathrm{~nm}^{2}$ and that of cholesterol was $0.223 \mathrm{~nm}^{2}$ ), and that of the I-quartet (not including the alkyl chain) was estimated as $0.7 \mathrm{~nm}^{2}$. The initial mass ratio of channels/lipids was $1 / 1$. Provided $78 \%$ of lipids and only $12.7 \%$ of the HC8 channels remained in the purified the vesicles, the real mass ratio of channels/lipids was $\sim 1 / 6$. The average molecular weight of lipid is $484 \mathrm{Da}$ and the molecular weight of the channel quartet is 12,768 Da (48 HC8 molecules assembled as a channel based on simulation). The molar lipids to channel ratio is 134.3. The insertion number of the channel was $\sim 1,528$ per vesicle. If the overall net permeability by channels in liposomes was $0.96 \mu \mathrm{m} / \mathrm{s}$, the single-channel permeability was $4.0 \times 10^{-17} \mathrm{~cm}^{3} / \mathrm{s}$ and $1.4 \times 10^{6}$ water molecules/s;
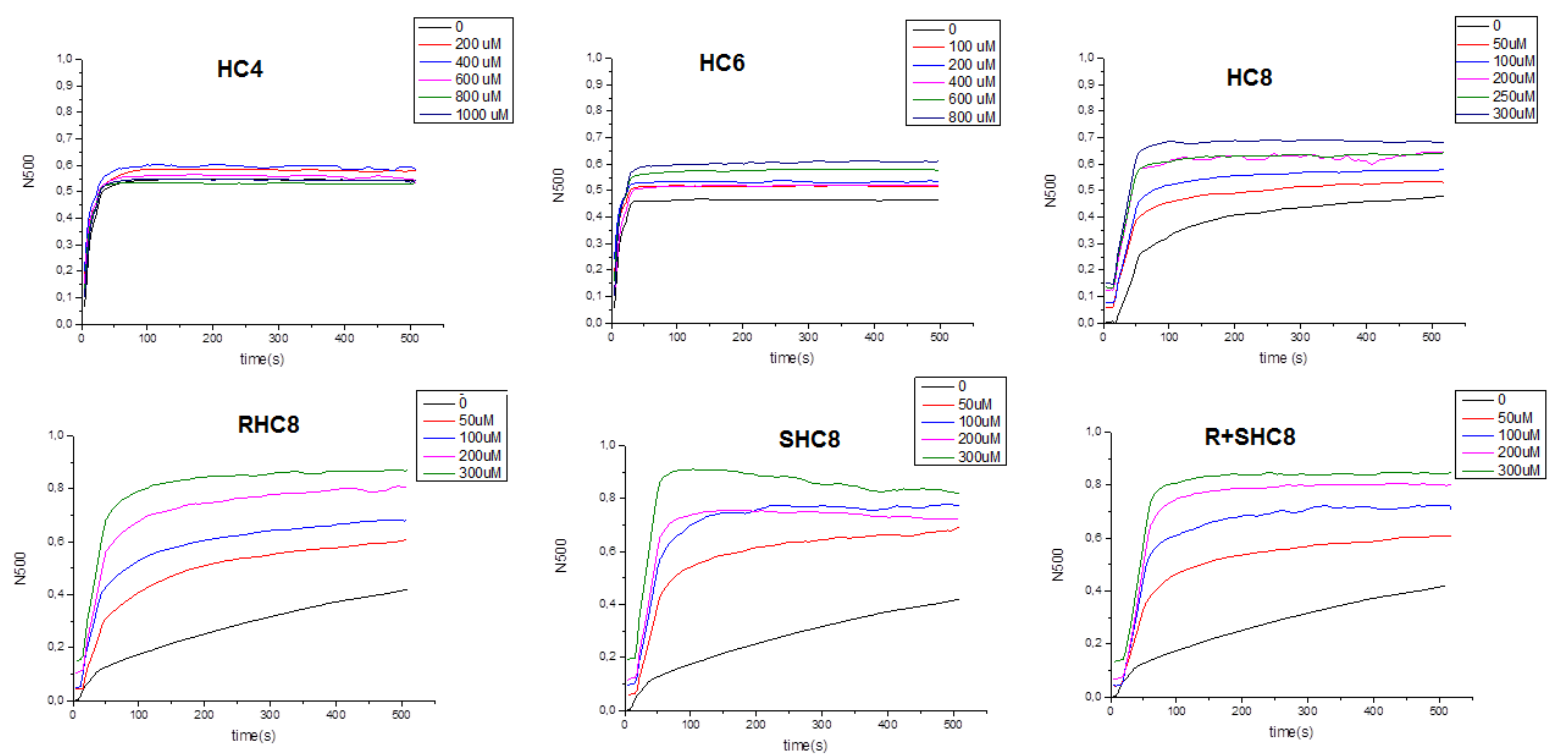

Figure S5. Ratiometric fluorescence curves of different concentrations $(\mu \mathrm{m})$ of the imidazole compounds using HPTS assay. The signal $\left(\mathrm{N} 500=I / I_{0}\right)$ was normalized at $t=500 \mathrm{~s}$. 


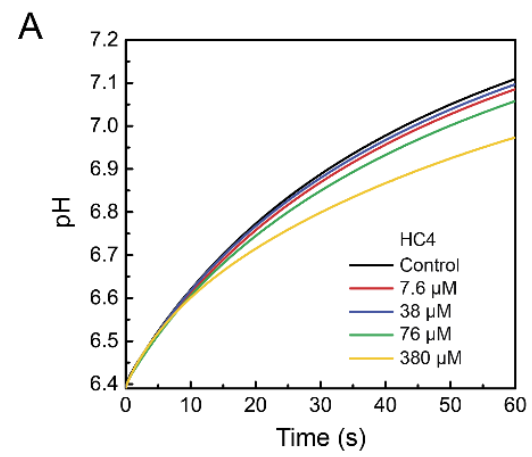

$\mathrm{D}$

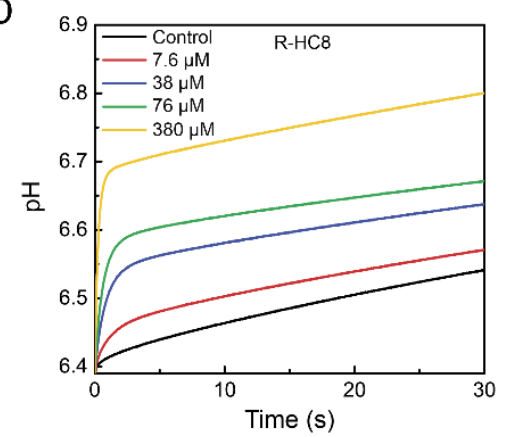

B

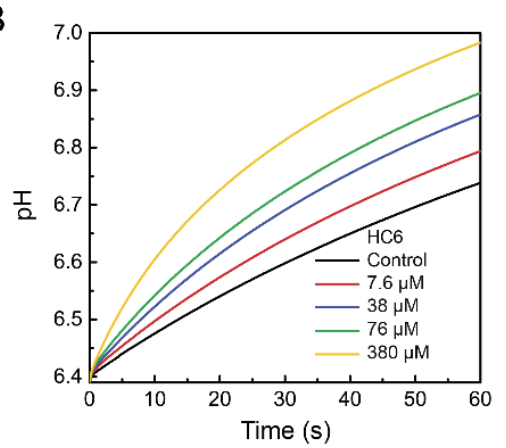

C

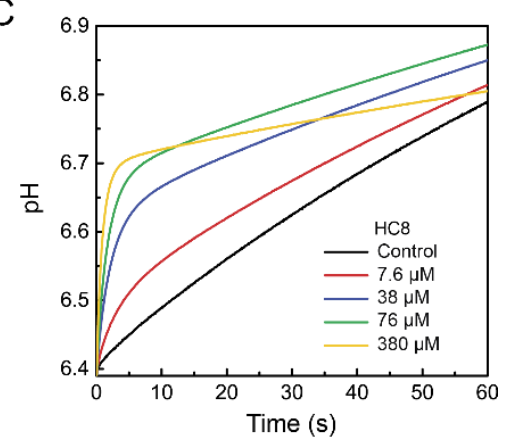

$\mathrm{E}$

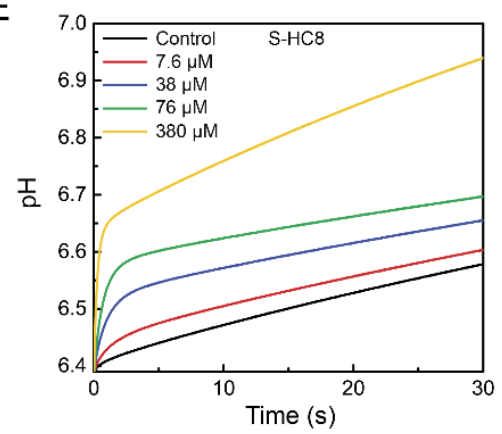

Figure S6. The proton transport activity of the channels assembled by different imidazole compounds were determined by stopped-flow experiments using fluorescent dextran assay (stopped-flow data shown are single traces). The $\mathrm{pH}$ inside the liposomes $(\mathrm{pH}=6.4)$ with the incorporated channels increased over time upon exposure to higher $\mathrm{pH}$ environment $(\mathrm{pH}=7.4)$, indicating the proton transport.

Table S3 Hill number and $\mathrm{EC}_{50}$ of the imidazole channels from HPTS assay

\begin{tabular}{ccc}
\hline & Hill number & $\mathrm{EC}_{50}(\mu \mathrm{M})$ \\
\hline HC4 & NA & NA \\
HC6 & 0.49 & 269.4 \\
HC8 & 0.74 & 121.5 \\
R-HC8 & 0.50 & 69.5 \\
S-HC8 & 0.21 & 11.2 \\
R-HC8 and S-HC8 & 0.42 & 28.2 \\
\hline
\end{tabular}




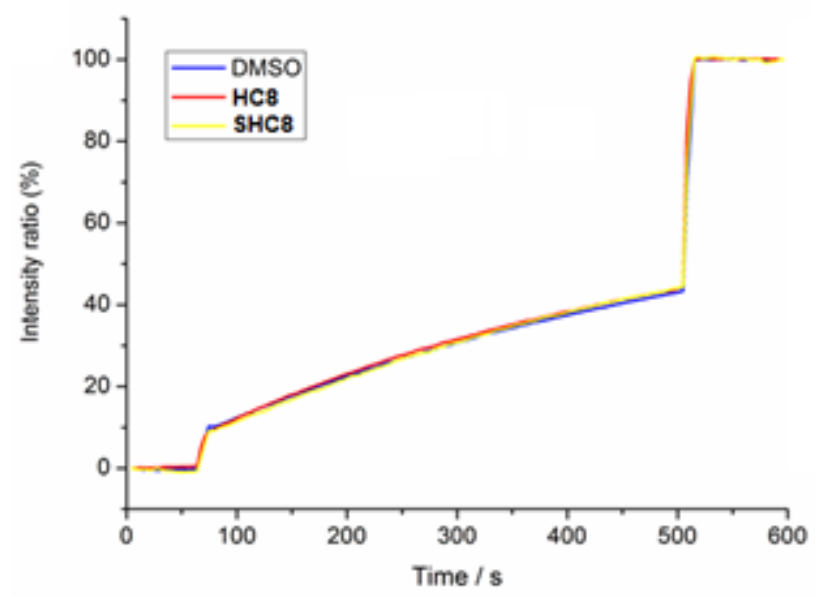

Figure S7. A. Transport of $\mathrm{Na}^{+}$ions as determined in a $\mathrm{pH}$ gradient assay. POPC liposomes $(100 \mathrm{~nm})$ containing HPTS dye $(0.1 \mathrm{mM})$ in $100 \mathrm{mM} \mathrm{NaCl}, 10 \mathrm{mM}$ sodium phosphate $\mathrm{pH}=6.4$ were suspended $100 \mathrm{mM} \mathrm{LiCl}, 10 \mathrm{mM}$ sodium phosphate $\mathrm{pH}=6.4$. The compounds, $\mathrm{HC} 8$ and S-HC8 (red, yellow line) ( $40 \mathrm{mM}$ ), were added at $t=60 \mathrm{~s}$ and the addition of $\mathrm{NaOH}$ solution at $t=75 \mathrm{~s}$ established an external $\mathrm{pH}=7.4$. At $t=520 \mathrm{~s}$ the bilayer membrane (BLM) were destroyed with Triton $\mathrm{X}-100$ detergent. The background experiment was performed by using pure POPC/DMSO liposomes. Measurement of the ratiometric fluorescence intensity of HPTS $\left(\lambda_{\mathrm{ex}, 1}=405 \mathrm{~nm}, \lambda_{\mathrm{ex}, 2}=450 \mathrm{~nm}, \lambda_{\mathrm{em}}=510 \mathrm{~nm}\right)$ allowed the determination similar transport profiles to the solvent. 


\section{Molecular Dynamics simulations.}

\section{Method}

System preparation : Currently many unknowns about the nature of the active I-quartet aggregates exist and make it difficult to build a precise model. Here, our intention was to explore the properties of the simplest and smallest assemblies that seem plausible. Four differents systems were built using $\mathrm{HC} 6, \mathrm{HC}$, R-HC8, and S-HC8 I-quartets crystal structures. The Mercury 3.5.1 software was used to fill the crystallographic unit cell with missing molecules. The unit cell was then replicated, keeping 2, 6 and 8 slices in $x, y$ and $z$ axis directions, respectively, resulting in a 96 molecule patch. The four systems HC6, HC8, R-HC8 and S-HC8, include respectively 2, 2, 6 and 6 water channels. It should be noted that for the 6 water channels of the RHC8 and SHC8 systems, two were facing the membrane. The four systems were then inserted in a preequilibrated triclinic membrane patch containing POPC/POPS/Cholesterol molecules with a 5/4/1 ratio. Overlapping water and lipid molecules were deleted. A concentration of roughly $50 \mathrm{mM}$ of $\mathrm{Na}^{+} \mathrm{Cl}^{-}$was added to the solvent, in addition to $\mathrm{Na}^{+}$ions required to neutralize the system charge due to the negatively charged POPS lipids.

Molecular Dynamics simulation conditions: Simulations were performed using the CHARMM-36 force field (S7) for lipid molecules and the TIP3P model (S8) for water. To represent the HC6, HC8, R-HC8 and S-HC8 molecules, and generate their topologies, we used the CHARMM General Force Field (CGenFF) (S9) together with the paramchem webservice (S10). The GROMACS 4.6 software (S11) was used to run the simulations using virtual interaction sites allowing a $5 \mathrm{fs}$ integration time step. All bonds were constrained using the LINCS algorithm. Particle mesh Ewald electrostatics was used with a $10 \AA$ cutoff with the Verlet buffer scheme for non-bonded interactions, the neighbor list was updated every 20 steps. Three baths (imidazoles, lipids, water and ions) were coupled to a temperature of 310 $\mathrm{K}$ using the Bussy velocity rescaling thermostat with a time constant $\tau=0.1 \mathrm{ps}$. Pressure in the $x / y$ dimensions was scaled isotropically with a Berendsen weak barostat and the $z$ dimension was coupled independently to a reference presssure of $1 \mathrm{bar}, \tau=5.0 \mathrm{ps}$ and compressibility of $4.510^{-5} \mathrm{bar}^{-1}$. For the systems simulated with a varying lateral pressure of $10 / 10 / 100$ bar, only the $x / y$ dimension pressure was affected. All systems were minimized for 10.000 steps with a steepest descent algorithm and equilibrated for $20 \mathrm{~ns}$, using position restraints of $1000 \mathrm{~kJ} \cdot \mathrm{mol}^{-1} \cdot \mathrm{nm}^{-2}$ on heavy atoms, with the crystal structure as a reference. Production runs were finally computed with simulation times varying from 250 ns to $1 \mu \mathrm{s}$ without any position restraints. Overall simulation system composition, pressure and simulation times are indicated in Table S4. 
Table S4 : Simulation systems overview.

\begin{tabular}{llccc}
\hline Acronym & $\begin{array}{l}\text { Composition } \\
\text { (Imid./Chol./POPC/POPS/water) }\end{array}$ & Atom number & Pressure (atm) & Sim. time (ns) \\
\hline HC6_P1 & $96 / 148 / 111 / 28 / 8442$ & 58496 & 1 & 1000 \\
HC6_P-10 & $96 / 148 / 111 / 28 / 8442$ & 58496 & -10 & 250 \\
HC6_P10 & $96 / 148 / 111 / 28 / 8442$ & 58496 & 10 & 500 \\
HC6_P100 & $96 / 148 / 111 / 28 / 8442$ & 58496 & 100 & 500 \\
HC8 & $96 / 155 / 114 / 32 / 8534$ & 60780 & 10 & 1000 \\
S-HC8 & $96 / 148 / 119 / 32 / 8608$ & 61154 & 10 & 500 \\
R-SC8 & $96 / 147 / 119 / 32 / 8589$ & 61023 & 10 & 500 \\
\hline
\end{tabular}

\section{Complementary Observations}

Pressure dependence in the HC6 system: Visual inspection shows that initial water channels of HC6 I-quartets (Fig. S8A) are lost after around 90, 103 and 109 ns at -10, 1 and 10 atm, respectively, while at 100 atm the I-quartets are much better preserved, one is fully intact at the end of the simulation ( $250 \mathrm{~ns}$ ), the other has started to disassemble and loose some of its water. Structure loss is quantified in the plot of Fig. S8A and S8B. The radial distribution functions in Fig. S8D characterize this increasing structural disorganization in more detail.

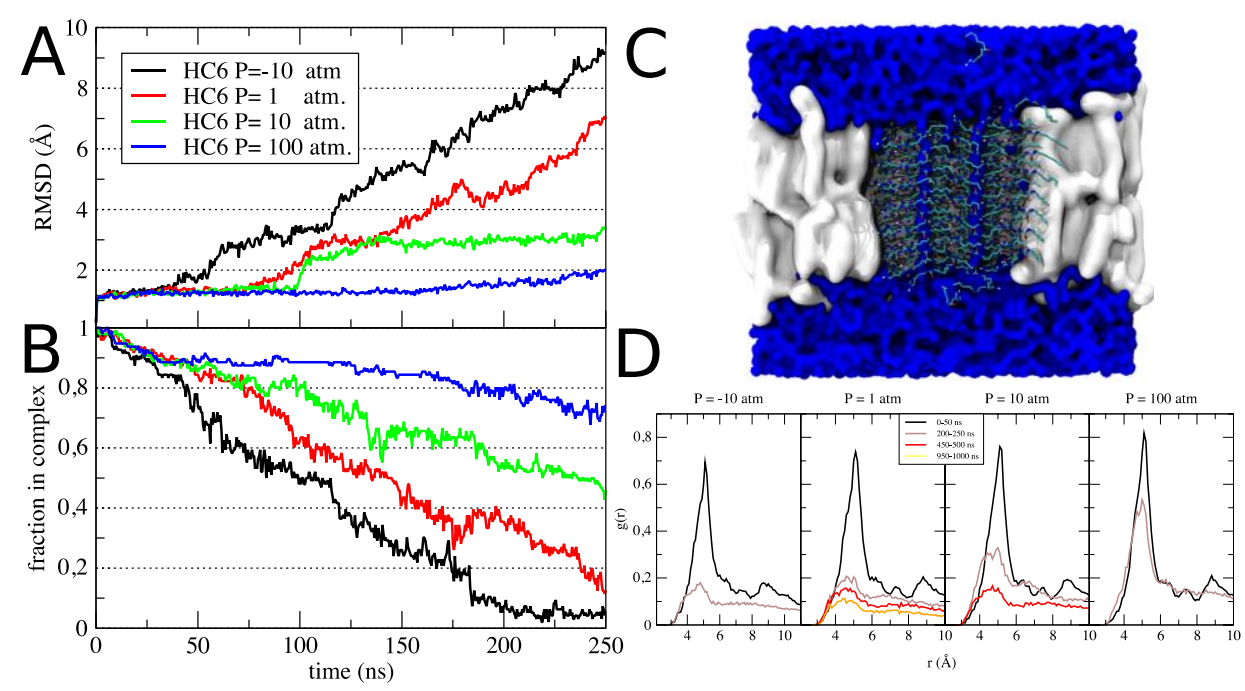

Figure S8. Loss of initial structure of HC6 I quartet channels, measured as RMSD (A) of the half more stable molecules and as fraction organized as in the crystal (B) is shown for the first 250 ns of the pressure-dependent simulations at $-10,1,10$ and 100 atm. C. A typical cross-section of the HC6 simulation system illustrates how water (blue surface) connects through artificial channels traversing the IMID aggregate (atom-colored licorice representation) held together by the membrane (white surface). D. Radial distribution functions of IMIDN17 atoms for different time intervals of the simulation covering the beginning and end of each simulation. 
The behavior of the inner water molecules is coupled to the structuring of the HC6 I-quartets assembly, similarly affected by the pressure: the more structure is retained with higher pressure, the more water transport is impeded, in particular at 100 atm as shown in Fig. S9. On the other hand, initial high water permeation in the loosely structured HC6 I-quartet assembly, on the longer timescale, leads to high desorganisation and in turn strongly affects water transport: the permeation (\#water leaks) for HC6 with a latteral pressure of $1 \mathrm{~atm}$ (Figure S9-S10), after $400 \mathrm{ns,} \mathrm{is} \mathrm{almost} \mathrm{totally} \mathrm{impeded.}$

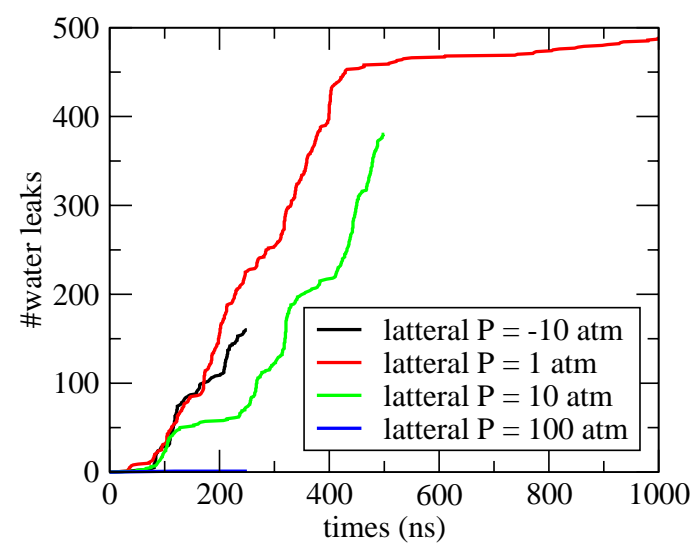

Figure S9. The water transport activity time series of the HC6 channels under increasing lateral pressure, from -10 atm to $100 \mathrm{~atm}$ is shown. Cumulated transport of water molecules across the membrane, in either direction are shown.

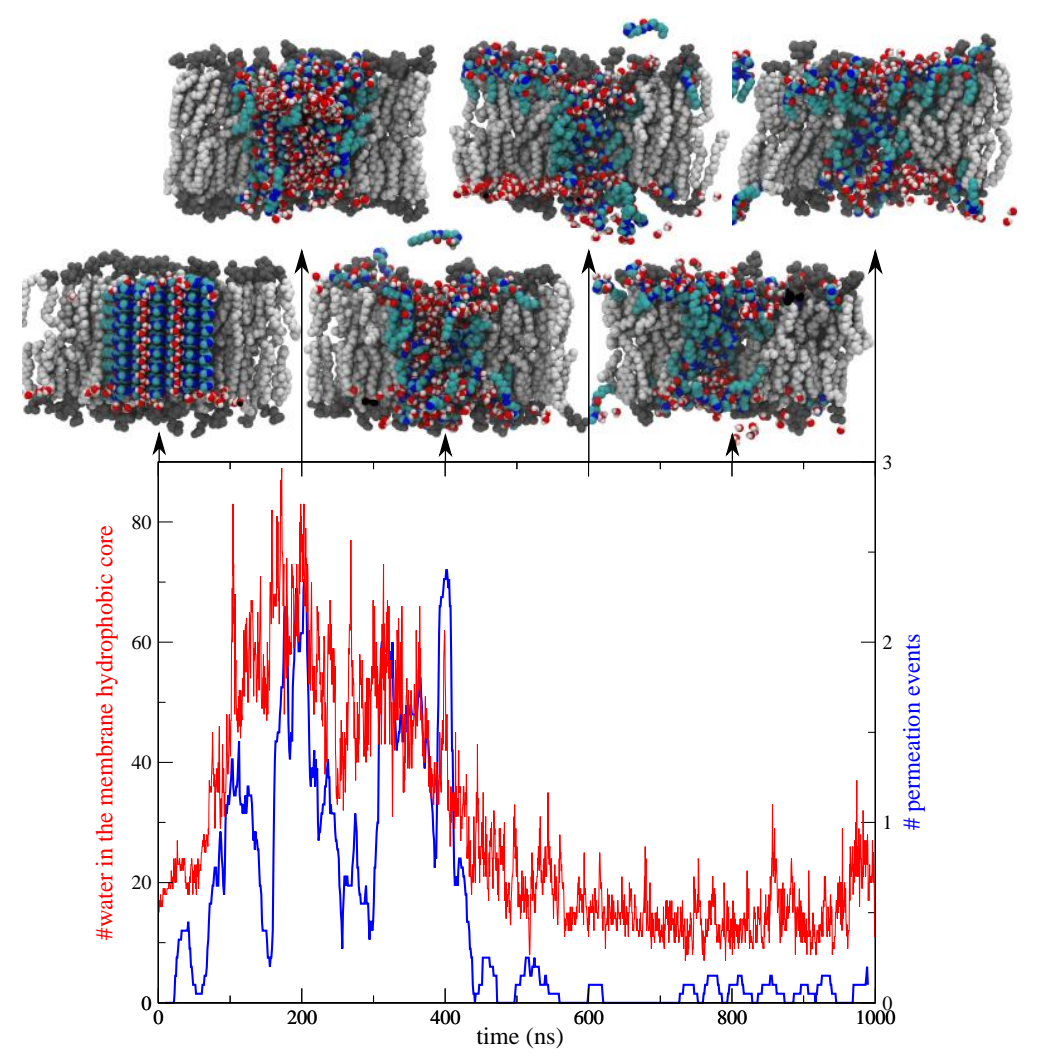

Figure S10. Detailed water transport activity time series of the HC6 system at 1atm lateral pressure. Passage of water molecules across the membrane is shown in blue (for clarity the curve was averaged on a 20 ns window), number of water molecules in the hydrophobic core is shown in red. On the upper panel a snapshot of the system is shown every $200 \mathrm{~ns}$, for clarity only half the HC6 molecules are shown. 
We therefore chose $10 \mathrm{~atm}$ for subsequent simulations, to stabilize the aggregate structures, yet preserve the possibility of water transport at the simulation timescale of ca. 1 microsecond. Analysis of these simulations also revealed that initial cholesterol placement may be important, because the lipid-exposed area of the patches is quite important compared to their bulk and cholesterol binds and potentially stabilizes the membrane facing regions.
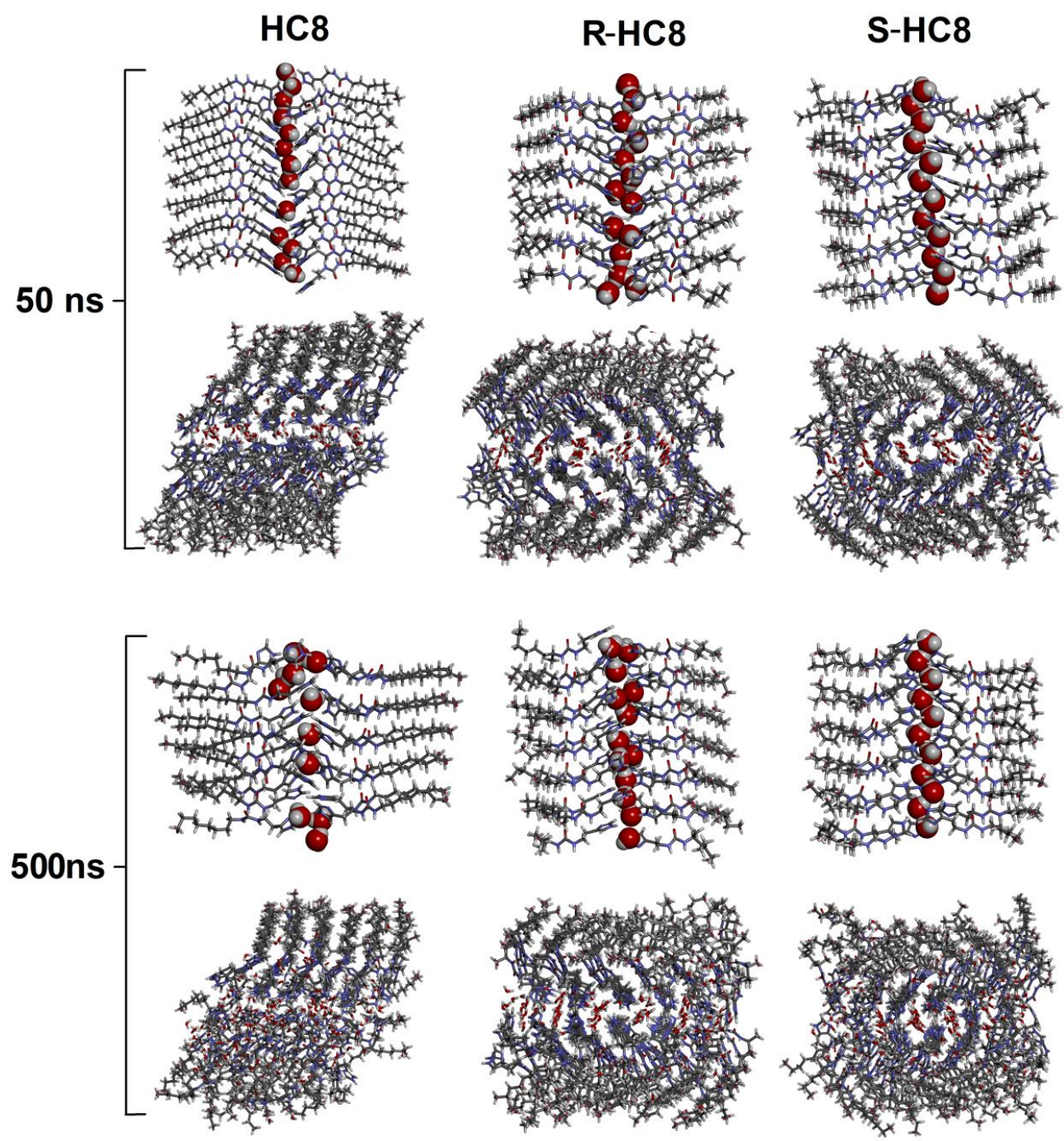

Figure S11. I-quartet channels structures in stick representation, water CPK representation (top row) and their molecular packing (bottom row) obtained after $50 \mathrm{~ns}$ (top) and $500 \mathrm{~ns}$ (bottom) molecular dynamics simulations at 10 atm of the HC8, R-HC8 and S-HC8 X-ray crystal structures embedded in the bilayer membrane environment.

Superstructure stability, water wire structure and orientation in the HC8, S-HC8 and R-HC8 systems : As described in the main text, the longer alkyl chains in the HC8, R-HC8 and S-HC8 systems favor a more pronounced superstructure and more stable water wires. Initial and final snapshots at 50 and 500 ns of these I-quartet systems are shown in Fig. S11, with an emphasis on highlighting the water wire. The chiral systems undergo a twist of the superstructure. The structural drift is quantified in Fig. S12, the R-HC8 system being the most stable one, followed by S-HC8, whereas HC8 is more stable than HC6 on longer timescales 
(>250 ns) in terms of RMSD. The analysis of the radius of gyration of the superstructure confirms this trend. The stability of the water wires is more specifically depicted in Fig.S13.

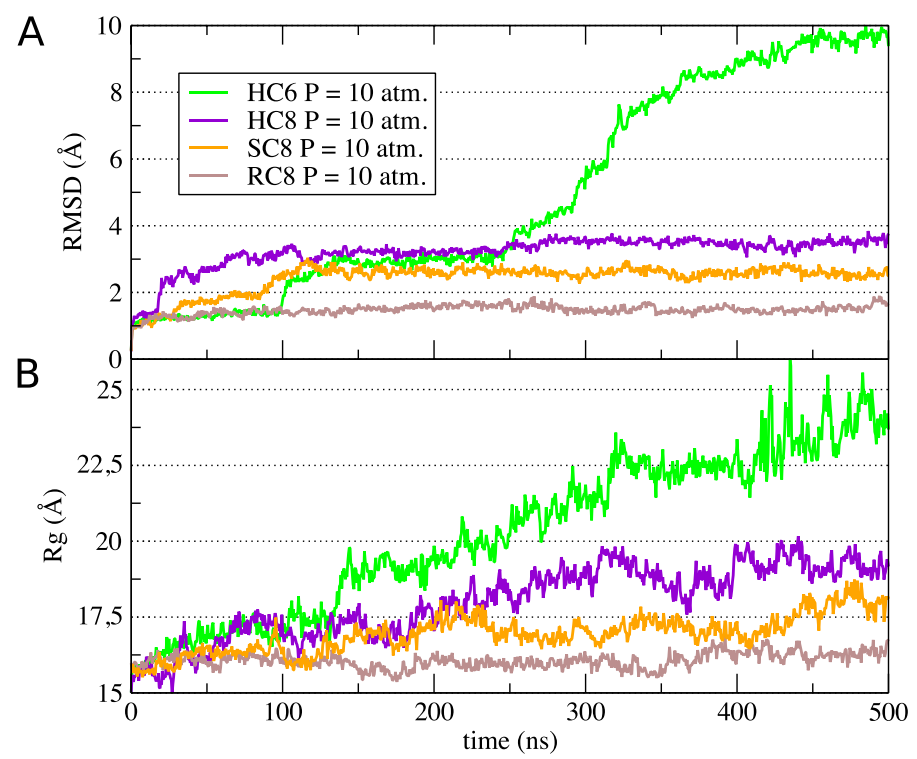

Figure S12. Time series of the structural drift of HC6, HC8, R-HC8, S-HC8 I quartet channels, measured as A. RMSD or as B. radius of gyration of the IMID N17 atoms at 10 atm.

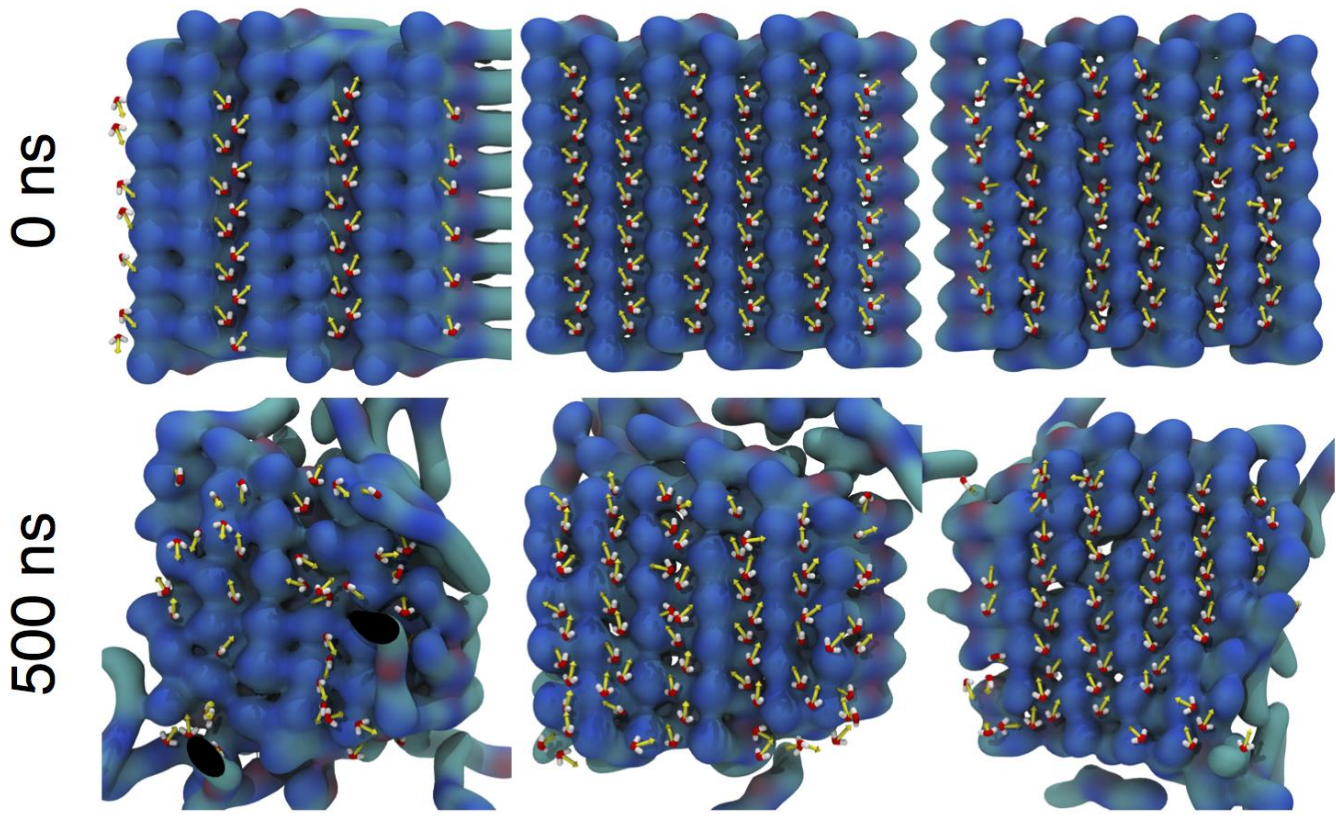

Figure S13. Final water-wire (red/white sticks) and dipole (yellow arrows) orientations within the I-quartet HC8, R-HC8 and S-HC8 channels (bluish surface).

The difference between HC6, where water wire structuring is clearly lost, and the chiral SHC8 and R-HC8 superstructures maintaining a strong ordering of the wires is marked. By construction the water wires at the right-most and left-most positions - in direct contact with the lipid environment - are structurally more labile. A semi-quantitative analysis is performed in terms of one-dimensional water density of permeating water molecules in the membrane region shown in Fig. S14A; immobile water molecules are discarded from this 
analysis. The difference between $\mathbf{H C}$ and $\mathbf{R}-\mathbf{H C}$ or S-HC8 is again very apparent and even differences among channels are clearly visible. Not only are these wires clearly structured in the chiral systems, but their orientation is tightly controlled as well, as depicted in Fig. S14B.

A

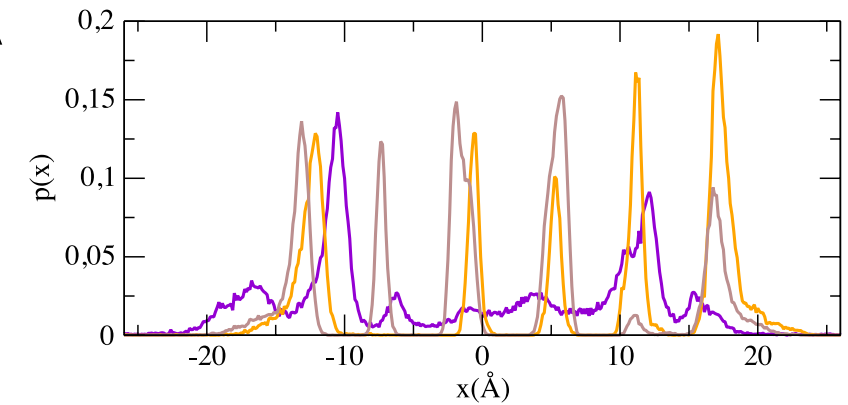

B

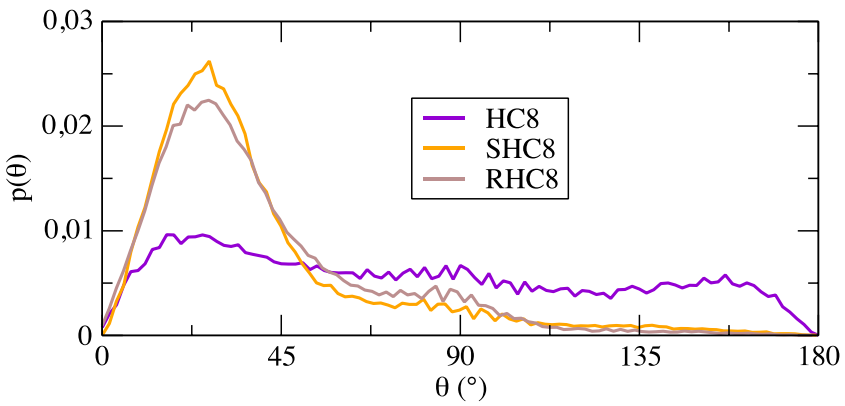

Figure S14. A. One-dimensional water density profile for crossing water averaged for the simulations of the HC8, R-HC8 and S-HC8 channels at 10 atm. B. Water dipolar moment orientation with respect to the $\mathrm{z}$ axis perpendicular to the membrane - only channel water is used for this calculation.

Water transport across HC8, S-HC8 and R-HC8 systems: We characterized water transport first globally, through counting overall passage of water molecules through the membrane in either direction (Fig. S15A). A more nuanced picture, separating the membrane-exposed lateral channels from the central two well shielded channels reveals that structured water wire transport is observed for the R-HC8 system in particular. The S-HC8 system - compared to the reference background of unstructured HC8 - does not establish transport in the current simulation timescale, in agreement with the experimental observation of a slow buildup.
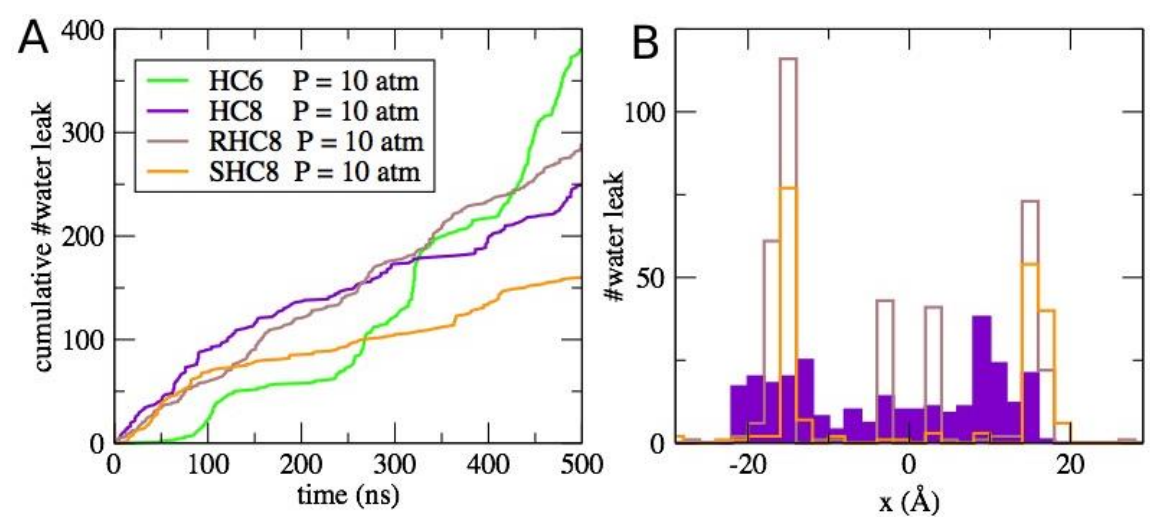

Figure S15. A. The water transport activity time series of the I-quartet channels is shown as cumulated passage of water molecules across the membrane, in either direction. B. shows the count of permeation events for each water wire along the membrane width ( $x$-axis). 


\section{SUPPLEMENTARY REFERENCES}

S1. M. C. Woodle, D. Papahadjopoulos, in Methods Enzymol. Vol. 171 (ed Becca Fleischer Sidney Fleischer, Academic Press) pp. 193-217 (1989).

S2. P. Latimer, B. E. Pyle, Biophys. J. 12, 764-773, (1972).

S3. M. J. Borgnia, D. Kozono, G. Calamita, P.C. Maloney, P. Agre. J. Mol. Biol. 291, 1169-1179, (1999).

S4. M. B. Lande, J.M. Donovan, M.L. Zeidel, J. Gen. Physiol. 106, 67-84, (1995).

S5. A.Hulanicki, M. R. Masson, Reactions of acids and bases in analytical chemistry. (E. Horwood ed.) (1987).

S6. S W Chiu, E. Jakobsson, R J. Mashl, and H L. Scott, Biophys. J. 83, 1842-1853, (2002).

S7. J. B. Klauda, R. M. Venable, J. A. Freites, J. W. O'Connor, D. J. Tobias, C. Mondragon-Ramirez, I. Vorobyov, A. D. Mackerell Jr. and R.W. Pasto, J. Phys. Chem. B, 114, 7830-7843, (2010).

S8. W. L. Jorgensen, J. Chem. Phys. 79, 926-935 (1983).

S9. K. Vanommeslaeghe, E. Hatcher, C. Acharya, S. Kundu, S. Zhong, J. Shim, E. Darian, O.

Guvench, P. Lopes, I. Vorobyov, A. D. Mackerell Jr. J. Comput. Chem. 31, 671-690, (2010).

S10 K. Vanommeslaeghe, E. Prabhu Raman, and A. D. MacKerell Jr. J. Chem. Inf. Model., 52, 3155-3168 (2012).

S11. B. Hess, C. Kutzner, D. van der Spoel, and E. Lindahl, J. Chem. Theory Comp. 4, 435-447, (2008). 